\title{
The Influence of Credit Scores on Dividend Policy: Evidence from the Korean Market
}

\author{
Taekyu KIM*, Injoong KIM** \\ Received: August 06, 2019 Revised: December 11, 2019 Accepted: December 18, 2019
}

\begin{abstract}
The paper investigates the mechanism through which corporate credit ratings affect dividend payments by decomposing the mean difference of dividends into a part that is explained by the determinants of dividends and a residual part that is contributed by the pure credit group effect, in the framework of the traditional dividend model of Fama and French (2001). Historically, better credit rated firms have shown consistently higher propensity to pay dividends especially during the economic crisis period. According to the counter-factual decomposition technique of Jann (2008), better rated firms are more responsive to the firm characteristics that have positive impact on dividends and poor rated firms are more responsive to the negative dividend predictors. As a result, good (bad) credit ratings make corporate managers become more bold (timid) in their dividend payments and they tend to pay more (less) dividends than what their firm characteristics prescribe. The degree of information asymmetry increases for the poor group firms during crisis periods and they attempt to reserve more cash in preparation for future investments. The decomposition results suggest that the credit group effect can potentially exceed the effect of firm characteristics because firms of different credit ratings can respond to the very same firm characteristics in a different manner.
\end{abstract}

Keywords : Credit Rating, Dividend, Financial Crisis, Firm Characteristic, Information Asymmetry

JEL Classification Code : G01, G10, G30, G35

\section{Introduction}

Historically, the investment grade firms have shown much higher chance of dividend payments than the junk grade firms. In our sample, the KIS-value category of 'good' credit rated firms show on average $88.4 \%$ chance of dividend payments, while the 'moderate' and the 'junk' rated firms show only $57.9 \%$ and $13.6 \%$ chance of dividend payments, respectively (Korea Information Service, KIS is a professional credit rating agency in Korea). This gap in the dividend payments becomes even wider during economic crisis periods. A natural question arises of

*First Author. Professor, Department of Finance, College of Business, Hallym University, Korea. Email: tkim@hallym.ac.kr ** Corresponding Author. Assistant Professor, College of Business Management Finance \& Insurance, Hongik University, Korea [Postal Address: 2639 Sejong-ro, Jochiwon, 30016, Korea]. Tel:+82-44-860-2273, Email: kij@hongik.ac.kr ๑) Copyright: Korean Distribution Science Association (KODISA)

This is an Open Access article distributed under the terms of the Creative Commons Attribution NonCommercial License (https://creativecommons.org/licenses/by-nc/4.0/) which permits unrestricted noncommercial use, distribution, and reproduction in any medium, provided the original work is properly cited. whether this gap can be explained solely by the difference in the endowment of firm characteristics, such as size and profitability, or if there exists any systematic difference or discrimination between different credit rating groups. To explain the dividend difference, we start on the traditional dividend model of Fama and French (2001) and decompose the dividend difference into a part that can be explained by the difference in the firm characteristics, and the residual part that is attributable to the credit group effect. Blinder (1973), Oaxaca (1973) and Jann's (2008) decomposition technique allows us to verify what proportion of the dividend difference is due to firm characteristics and what proportion of it is due to the credit group effect. The magnitude of this credit group effect relative to the contribution of firm characteristics is analyzed over both the crisis and the non-crisis period.

The empirical results suggest that there exists a systematic difference in dividend payments between different credit rating groups that is not fully explained by firm characteristics. Better credit rated firms are generally larger, more profitable, less risky and more mature firms 
with limited investment opportunities. All these firm characteristics support their higher chance of dividend payments. However, when we calculate the hypothetical probabilities of dividend payments for these firms assuming that they belonged to the lower credit rated groups, their chance of dividend payments is reduced significantly even with the same level of firm characteristics. In particular, this phenomenon becomes more evident during the crisis period. Better rated firms not only have a higher level of positive dividend determinants, but also they are more responsive to the firm characteristics that have positive impact on dividends. On the contrary, poor rated firms are more responsive to the firm characteristics that are expected to reduce dividends. As a result, all our 100 portfolios of firms show elevated probabilities of dividend payments when assumed to be upgraded in their credit ratings even with the same firm characteristics.

Firm characteristics of the traditional dividend forecast model explain a firm's dividend policy fairly well during the non-crisis period. However, for the crisis period, their explanatory power drops significantly and the credit group effect plays a major role in the dividend policy. While the investment grade firms show no deterioration in the information asymmetry during the crisis period, the degree of information asymmetry increases significantly for the junk rated firms. The conservative dividend policy of the junk grade firms during the crisis period is believed to be linked with this elevated level of information asymmetry because the external financing is most difficult during this period. It is likely that corporate managers seriously consider the credit ratings when they set up a dividend policy, and especially during crisis periods, credit ratings may explain dividend policies more accurately than do the firm characteristics of the traditional dividend forecast model.

This paper deserves credit in the sense that it identifies the existence of the credit group effect by decomposing the dividend difference and measures the magnitude of it over both the crisis and the non-crisis periods. Our results suggest that the credit group effect can potentially dominate the effect of firm characteristics particularly during the crisis period. Therefore, the simple application of the traditional dividend forecast model that assumes homogeneous reaction of firms to the common firm characteristics may fail to accurately reflect firms' dividend policy. Credit ratings change the way a firm respond to firm characteristics, and particularly during the crisis period, it is crucial to take this effect into consideration because firm environment, such as risk and information asymmetry, changes dramatically. The remainder of this paper is organized as follows. Section 2 reviews the literature. Section 3 describes the empirical method. Section 4 presents and discusses the main results. Section 5 concludes.

\section{Literature Review}

\subsection{Review of Traditional Dividend Forecast Models}

The traditional dividend forecast model has been developed to explain the disappearing dividend phenomenon in US since 1978. The proportion of dividend payers in 1978 was $66.5 \%$ and it decreases to $20.8 \%$ in 1999. Fama and French (2001) incorporate firm size, profitability, and investment opportunity in their logit model as the key firm characteristics that affect dividend payments. However, after controlling for these firm characteristics, firms after 1978 are still less likely to pay dividends. Lower propensity to pay dividends has long been an enigma and many researchers have tried to find a new firm characteristic that can better explain dividends.

DeAngelo, DeAngelo, and Stulz (2006) developed a lifecycle theory of dividends and argue that the retained earnings to total equity ratio (RE/TE) can better explain dividends. In their regression model, RE/TE has a significant relation with dividend payments even after controlling for the measures of Fama and French (2001). Furthermore, in their portfolio approach, the marginal impact of RE/TE turns out to be greater than that of profitability and investment opportunity. A decrease in firms with positive retained earnings since 1978 coincides with the disappearing dividends and it is believed that the firm maturity is also a key determinant of dividends (Grullon, Michaely, \& Swaminathan, 2002).

Baker and Wurgler (2004) suggest that firms cater to investors' time varying preference for dividends by adjusting dividends over time. They argue that the evolution of historical dividend premium can explain the disappearing dividends. However, Hoberg and Prabhala (2009) view the investors' fads for dividends as a proxy for risk and explicitly add risk to the baseline dividend model. Absent for the risk control, proxies for the investors' fads matter, but these proxies become insignificant once the risk is incorporated into the model. They conclude that the catering theory fundamentally has zero explanatory power. Tahir and Mushtaq (2016) also emphasize the importance of the risk as a determinant of dividend payouts. Based on the literature, it is reasonable to use an extended model that incorporates Fama and French's (2001) firm characteristics together with the risk and the lifecycle measure as the key dividend predictors.

\subsection{Credit Ratings and Dividend Policy}

Sufi (2009) suggests that credit ratings afford firms an access to capital markets by reducing the information asymmetry. As a result, the increased participation of 
uninformed lenders allows firms to increase investments, and thereby firms can grow their assets more rapidly. Khieu and Pyles (2016) study the marginal impact of the rating changes on the dividend and investment policies. They find that credit downgraded firms reduce both dividends and investments. However, for credit upgraded firms, investments increase, but dividend payments do not increase, suggesting an asymmetric dividend stickiness. Similarly, Shin, Lee, and Jung (2017) investigate the effects of credit rating changes using the sampled Korean firms. They find that while the rating upgrades have no significant effect on dividends, downgraded firms, especially when downgraded from investment grade to non-investment grade, are more likely to decrease dividends. Kim and Kim (2019) investigate the dividend behavior of the investment and the speculative grade firms and show that, all else being equal, investment grade firms tend to payout more dividends than do the speculative firms.

We move one step further than the existing literature by posing the possibility that the same firm can react to the same firm characteristics differently, depending on which credit category the firm belongs to and on which economic period the firm is going through. The traditional dividend forecast models implicitly assume that firms react to the common firm characteristics homogeneously, but we are releasing this assumption. In an attempt to explain the heterogeneous firm behaviors, we also investigate the evolution of the degree of information asymmetry for all categories of firms and link this to the decomposition results.

\section{Methodology}

\subsection{Data and Construction of the Dividend Forecast Model}

This study analyzes KOSPI (Korea Composite Stock Price Index) and KOSDAQ (Korea Securities Dealers Automated Quotation) listed firms that have credit rating information in the KIS-value data base. We include both listed and delisted firms to minimize the survival bias. Linear interpolation method is used to adjust annual values of firm characteristics for firms whose fiscal year end is not December. Firm size, profitability, and market to book ratio are the firm characteristic variables of Fama and French (2001). A lifecycle measure and risks are added to the base model following DeAngelo et al. (2006) and Hoberg and Prabhala (2009). Based on the credit scores, firms are categorized into three groups. KIS-Value credit classes of 1 , 2 and 3 (extremely strong, very strong, and strong) are classified as 'good' group. Classes of 8, 9 and 10 (currently vulnerable, highly vulnerable, and extremely vulnerable) are classified as 'junk' group, and the remaining classes are classified as 'moderate' group (Regarding opinion conflicts on credit ratings, refer to Park \& Yoo, 2019). The distinction between the moderate and the junk group is the conventional investment and non-investment classification, and we further divide the investment group into the good and the moderate group. For each group, the following dividend forecast model is estimated.

$$
\begin{aligned}
& \operatorname{Pr}(\text { payer }=1) \\
& =\operatorname{logistic}\left(\begin{array}{c}
\alpha+\beta_{1} \text { Size }+\beta_{2} \text { Profitability } \\
+\beta_{3} M / B+\beta_{4} \text { Risk }+\beta_{5} \text { RE } / T E
\end{array}\right)+\varepsilon
\end{aligned}
$$

Firm size is measured by the logarithm of total assets and earnings are normalized by total assets to represent profitability. Market to book ratio (M/B) is a measure of investment opportunity assessed by the market and a high value represents growth potential of a company. Following Hoberg and Prabhala (2009), we use the daily stock returns to derive fitted returns and residual errors in the market model. The standard deviation of a firm's fitted returns is used as systematic risk and the standard deviation of residual errors is used as a proxy for the idiosyncratic risk. Total risk is the sum of the systematic and the idiosyncratic risk. DeAngelo et al.'s (2006) lifecycle measure is the ratio of retained earnings to total equity (RE/TE). To maintain consistency across years, accounting values are adjusted by the consumer price index because the analyses are based on the pooled data sets. In addition, we winsorize values at $1 \%$ and $99 \%$ level to minimize the effect of extreme values.

\subsection{Empirical Method of Decompositions}

The counter-factual decomposition of the mean difference is based on Erikson, Goldthorpe, Jackson, Yaish, and Cox (2005) and Jann (2008). The main approach is to divide the dividend gap between different groups into a part that is explained by firm characteristics and the residual part. For example, based on the regression model in equation (1), we can express the dividend difference between two groups as the difference in their firm characteristics and the residual part as follows.

$$
\begin{aligned}
\mathrm{E}\left[Y_{A}\right]-E\left[Y_{B}\right]= & \left\{E\left[X_{A}\right]-E\left[X_{B}\right]\right\}^{\prime} \beta^{*}+E\left[X_{A}\right]^{\prime}\left(\beta_{A}-\beta^{*}\right) \\
& +E\left[X_{B}\right]^{\prime}\left(\beta^{*}-\beta_{B}\right)
\end{aligned}
$$

From the linear regression model $Y=X^{\prime} \beta+\varepsilon$, where $Y$ represents dividends and $X$ is a vector of firm characteristics, $\mathrm{E}\left[\mathrm{Y}_{\mathrm{A}}\right]-\mathrm{E}\left[\mathrm{Y}_{\mathrm{B}}\right]=\mathrm{E}\left[\mathrm{X}_{\mathrm{A}}\right]^{\prime} \beta_{\mathrm{A}}-\mathrm{E}\left[\mathrm{X}_{\mathrm{B}}\right]^{\prime} \beta_{\mathrm{B}}$ holds. With a little bit of manipulation, we can derive the equation (2). The first term on the right-hand side of the equation (2) is the proportion of the dividend difference contributed by the difference in the endowment of firm characteristics between the group A and 
B. The remaining terms on the right-hand side represent the residual difference in the dividend payment. $\beta^{*}$ represents the ideal vector of coefficients that can be applied universally to both groups. If $\beta^{*}=\beta_{\mathrm{A}}=\beta_{\mathrm{B}}$, then the last two terms disappear, and the group difference can be explained solely by the difference in the endowment level of firm characteristics. However, if the two groups have different sensitivity with respect to each firm characteristic (i.e. $\beta_{\mathrm{A}} \neq \beta_{\mathrm{B}}$ ), then there exists no universal $\beta^{*}$ that can make the last two terms both equal to zero. Therefore, the difference in dividends now can be decomposed into a part that is attributed to the difference in firm characteristics and the remaining part that is attributable to the sensitivity difference. We name the former the indirect effect and the latter the direct effect of the group.

In the estimation, since we cannot directly observe $\beta^{*}$, we consider two extreme cases of $\beta^{*}=\beta_{\mathrm{A}}$ and $\beta^{*}=\beta_{\mathrm{B}}$, and take the average of the two to derive the final result. This method is equivalent to choosing $\beta^{*}=1 / 2 \cdot \beta_{\mathrm{A}}+1 / 2 \cdot \beta_{\mathrm{B}}$ because the following holds.

$$
\begin{aligned}
\frac{1}{2} \cdot E\left[X_{A}\right]^{\prime}\left(\beta_{A}-\beta_{B}\right) & +\frac{1}{2} \cdot E\left[X_{B}\right]^{\prime}\left(\beta_{A}-\beta_{B}\right) \\
= & E\left[X_{A}\right]^{\prime}\left\{\beta_{A}-\left[\frac{1}{2} \cdot \beta_{A}+\frac{1}{2} \cdot \beta_{B}\right]\right\} \\
+ & E\left[X_{B}\right]^{\prime}\left\{\left[\frac{1}{2} \cdot \beta_{A}+\frac{1}{2} \cdot \beta_{B}\right]-\beta_{B}\right\}
\end{aligned}
$$

If $\beta^{*}=\beta_{\mathrm{B}}$, then the direct effect from the equation (2) is $E\left[X_{A}\right]^{\prime}\left(\beta_{A}-\beta_{B}\right)$. Similarly, if $\beta^{*}=\beta_{A}$, then the direct effect of the group is $E\left[X_{B}\right]^{\prime}\left(\beta_{A}-\beta_{B}\right)$. Taking the average of these two comprises the left-hand side of the equation (3). The righthand side is nothing but the direct effect of the group derived by plugging $\beta^{*}=1 / 2 \cdot \beta_{\mathrm{A}}+1 / 2 \cdot \beta_{\mathrm{B}}$ into the equation (2). All these expressions are focusing on the sensitivity difference (difference in $\beta$ ) and we can see that, together with the endowment levels, the sensitivity difference can contribute to the difference in dividends. The main approach of the counter-factual decomposition is to hypothetically set the firm characteristics on the level of one particular group, and then measure the pure effect of the group by comparing the sensitivity difference (i.e. from equation (3), $E\left[X_{A}\right]^{\prime}\left(\beta_{A^{-}}\right.$ $\left.\beta_{\mathrm{B}}\right)$ or $\left.\mathrm{E}\left[\mathrm{X}_{\mathrm{B}}\right]^{\prime}\left(\beta_{\mathrm{A}}-\beta_{\mathrm{B}}\right)\right)$.

\section{Results and Discussion}

\subsection{Correlation Results}

Table 1 presents correlations between key dividend predictors. On the upper right-hand side of the diagonal line are the Pearson correlations. Pairwise partial correlations that control for the effect of other variables are reported on the lower left-hand corner of the table. Large and profitable firms tend to be at the mature stage of their lifecycle. Firms with persistent profits over a long period of time will naturally accumulate earnings and as a result, more portion of total equity will be contributed by retained earnings. Partial correlation results report that, other things being equal, large firms are more profitable and less risky. On the contrary, firms at the beginning stage of lifecycle are generally small, unprofitable and exposed to greater risks, all of which typify them as non-dividend payers. M/B for starting firms are generally higher because the market gives premium to the firms with ample investment opportunity. Firms with high growth potential tend to cut down dividends for future investments.

Table 1: Correlations of firm characteristic variables

\begin{tabular}{|c|c|c|c|c|c|}
\hline Variables & Size & Profitability & M/B & Risk & RE/TE \\
\hline Size & 1 & $0.183^{*}$ & $-0.121^{*}$ & $-0.377^{*}$ & $0.175^{*}$ \\
\hline Profitability & $0.052^{*}$ & 1 & $-0.048^{*}$ & $-0.296^{*}$ & $0.359^{*}$ \\
\hline $\mathrm{M} / \mathrm{B}$ & $-0.038^{*}$ & $0.043^{*}$ & 1 & $0.221^{*}$ & $-0.109^{*}$ \\
\hline Risk & $-0.321^{*}$ & $-0.212^{*}$ & $0.183^{*}$ & 1 & $-0.219^{*}$ \\
\hline RE/TE & $0.078^{*}$ & $0.312^{*}$ & $-0.070^{*}$ & $-0.077^{*}$ & 1 \\
\hline \\
*Significant at 1\%
\end{tabular}

\subsection{Historical Pattern of Dividends}

Figure 1 reports the historical pattern of dividend payments for firms that belong to the 'good', 'moderate', and 'junk' category of credit ratings. Every year, the proportion of dividend payers for each group is plotted over the sample period 2000-2015. Throughout the entire period, better credit group consistently shows higher dividend payments. Especially, the gap between the 'junk' and the 'moderate' group is wider than the gap between the 'moderate' and the 'good' group. The 'moderate' and the 'good' group are both classified as investment grade, but the 'junk' group is considered as non-investment (speculative) grade.

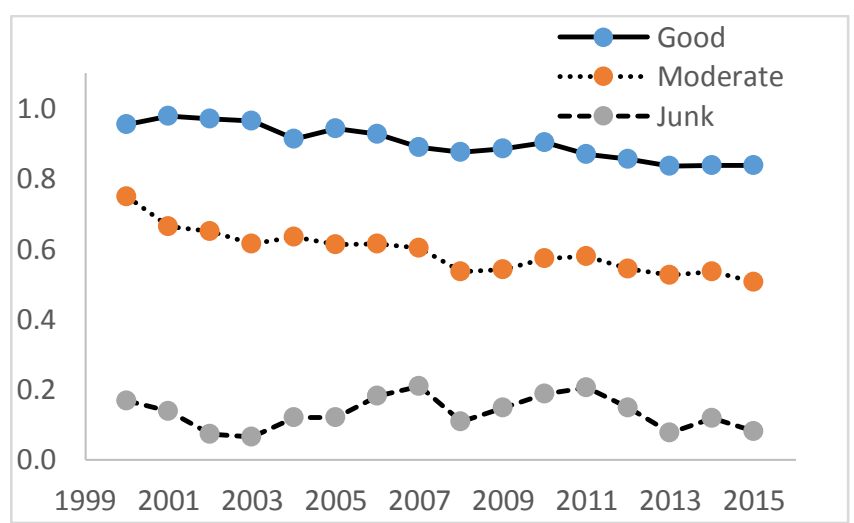

Figure 1: Historical pattern of dividends 
Another finding is that the poor credit group is more vulnerable to external shocks. The 'good' group maintains a very stable pattern of dividends over time, but the 'junk' group shows severe fluctuations particularly over the three economic crisis periods. IT bubbles in the early 2000s, followed by the global financial crisis in 2008, and the European financial crisis all seem to affect the 'junk' group more severely. The 'moderate' group lies between the 'good' and the 'junk' group both in the level and the volatility of dividends, suggesting that there exists a clear distinction between different credit rating groups. Here, the natural question arises of whether this persistent gap in the dividend payments can be solely explained by the difference in the firm characteristics, or if there exists any systematic difference not captured by the firm characteristics.

\subsection{Logit Regression Results}

Table 2 summarizes the relations between the dividend predictors and the probability of dividend payments in the framework of the traditional dividend forecast model. For each group, logit model is estimated separately for the sample period. Consistent with the correlation results in Table 1, firm size, profitability and RE/TE have positive relations with dividends, while risks and $M / B$ are negatively related with dividends in all three groups. One noticeable pattern is that for the positive dividend predictors, such as size, profitability and RE/TE, the sensitivity, or the magnitude of the coefficients is greater for the better rated group. For example, the sensitivity of dividends with respect to size is $0.186,0.377$ and 0.433 for the junk, moderate and good group, respectively. Similar patterns are observed for profitability and RE/TE variable.

Table 2: Dividend forecast models based on logit regressions

\begin{tabular}{|c|c|c|c|c|c|c|}
\hline & \multicolumn{2}{|c|}{ Junk } & \multicolumn{2}{c|}{ Moderate } & \multicolumn{2}{c|}{ Good } \\
\cline { 2 - 7 } & Coefficient & $\begin{array}{c}\text { Std. } \\
\text { error }\end{array}$ & Coefficient & $\begin{array}{c}\text { Std. } \\
\text { error }\end{array}$ & Coefficient & $\begin{array}{c}\text { Std. } \\
\text { error }\end{array}$ \\
\hline Intercept & $-2.535^{*}$ & 1.149 & $-5.867^{*}$ & 0.410 & $-6.495^{*}$ & 1.081 \\
\hline Size & $0.186^{*}$ & 0.054 & $0.377^{*}$ & 0.020 & $0.433^{*}$ & 0.056 \\
\hline Profitability & $0.111^{*}$ & 0.011 & $0.126^{*}$ & 0.004 & $0.072^{*}$ & 0.011 \\
\hline M/B & $-1.259^{*}$ & 0.268 & $-0.757^{*}$ & 0.048 & $-0.700^{*}$ & 0.077 \\
\hline $\begin{array}{c}\text { Systematic } \\
\text { risk }\end{array}$ & 0.098 & 0.106 & 0.033 & 0.036 & 0.027 & 0.093 \\
\hline $\begin{array}{c}\text { Idiosyncratic } \\
\text { risk }\end{array}$ & $-0.402^{*}$ & 0.066 & $-0.244^{*}$ & 0.020 & $-0.129^{*}$ & 0.051 \\
\hline RE/TE & $0.305^{*}$ & 0.070 & $1.282^{*}$ & 0.054 & $2.112^{*}$ & 0.230 \\
\hline *Significant at 1\% & & & & & \\
\hline
\end{tabular}

On the contrary, for the negative dividend predictors, such as risks and $\mathrm{M} / \mathrm{B}$, the magnitude of the coefficients is more negative for the lower rated group. For example, the coefficients for the idiosyncratic risk are $-0.402,-0.244$, and -0.129 and the coefficients for $\mathrm{M} / \mathrm{B}$ are $-1.259,-0.757$, and -0.700 for the junk, moderate and good group, respectively. This implies that higher rated firms react more positively to the positive dividend predictors and, at the same time, the lower rated firms react more negatively to the negative dividend predictors. Therefore, we can infer that two identical firms with the same level of firm characteristics may react differently depending on which credit group they belong to.

Table 3: Predicted and counter-factual proportions of dividends

\begin{tabular}{|c|c|c|c|c|c|c|}
\hline \multicolumn{7}{|c|}{ Panel A: All sample } \\
\hline \multicolumn{7}{|c|}{ Credit group } \\
\hline $\begin{array}{c}\text { Firm } \\
\text { characteristic }\end{array}$ & \multicolumn{2}{|c|}{ 1.Junk } & \multicolumn{2}{|c|}{ 2.Moderate } & \multicolumn{2}{|c|}{ 3.Good } \\
\hline 1.Junk & \multicolumn{2}{|c|}{0.136} & \multicolumn{2}{|c|}{0.347} & \multicolumn{2}{|c|}{0.519} \\
\hline 2.Moderate & \multicolumn{2}{|c|}{0.276} & \multicolumn{2}{|c|}{0.579} & \multicolumn{2}{|c|}{0.734} \\
\hline 3.Good & \multicolumn{2}{|c|}{0.423} & \multicolumn{2}{|c|}{0.781} & \multicolumn{2}{|c|}{0.884} \\
\hline \multicolumn{7}{|c|}{ Panel B: Crisis vs. Non-crisis period } \\
\hline & \multicolumn{3}{|c|}{ Crisis period } & \multicolumn{3}{|c|}{ Non-crisis period } \\
\hline $\begin{array}{c}\text { Firm } \\
\text { characteristic }\end{array}$ & Junk & Moderate & Good & Junk & Moderate & Good \\
\hline 1.Junk & 0.112 & 0.355 & 0.555 & 0.158 & 0.338 & 0.489 \\
\hline 2.Moderate & 0.206 & 0.568 & 0.754 & 0.342 & 0.587 & 0.718 \\
\hline 3.Good & 0.310 & 0.748 & 0.887 & 0.520 & 0.808 & 0.882 \\
\hline \multicolumn{7}{|c|}{ Panel C: Degree of information asymmetry } \\
\hline & \multicolumn{3}{|c|}{ Crisis period } & \multicolumn{3}{|c|}{ Non-crisis period } \\
\hline & Junk & Moderate & Good & Junk & Moderate & Good \\
\hline AI Index & 68.03 & 50.41 & 33.97 & 64.84 & 50.61 & 39.38 \\
\hline
\end{tabular}

Junk rated firms are weaker in dealing with risks and as a result, they seem to take a more conservative approach in paying dividends compared to better rated groups even if they face the same level of risks. Lower rated firms have difficulty in raising capital through an external financial market due to the severe information asymmetry. Therefore, they seem to reserve more internal cash by cutting down dividends as they face new investment opportunity (high $\mathrm{M} / \mathrm{B}$ ). Based on the results so far, it is reasonable to infer that not only the endowment level of firm characteristics, but also the sensitivity difference between different credit groups contribute to the corporate dividend policy. In this sense, the traditional dividend forecast model that lumps all the firms and derives a common dividend forecast model may fail to capture this systematic difference.

\subsection{Factual vs Counter-factual Dividend Payments}

Table 3 reports the predicted and the counter-factual proportions of dividend payments for each group. The diagonal elements are based on the factual distribution of firm characteristics and the factual conditional probabilities, while the off-diagonal elements are based on the counterfactual probabilities. For example, in panel $\mathrm{A}$, the actual proportions of dividend payers are $13.6 \%, 57.9 \%$ and $88.4 \%$ for the 'junk', 'moderate', and 'good' group, respectively. 
Here, the gap between the junk and the moderate group is wider than the gap between the moderate and the good group, suggesting that the investment and non-investment grade distinction generates bigger impact on dividends.

The movements along the vertical line are the changes due to firm characteristics and the movements along the horizontal line are the changes attributable to different credit rating groups. For example, junk firms are expected to pay dividends with the probability of $13.6 \%$, but if they had the same firm characteristics of the 'moderate' or the 'good' group, then the counter-factual, or the hypothetical probability of dividend payments would increase to $27.6 \%$, or to $42.3 \%$, respectively (vertical movement). Similarly, if the same junk firm were classified as the moderate or the good group without any change in the endowment of firm characteristics, then the counter-factual probability of dividend payments would be $34.7 \%$, or $51.9 \%$, respectively (horizontal movement). Finally, if the same junk firm had the same firm characteristics as the moderate or the good group and at the same time if it had the same conditional probabilities as the moderate or the good credit group, then the most reasonable estimate of the probability of dividend payments would be $57.9 \%$ or $88.4 \%$, which is the actual probability of dividends for the moderate and the good group. Therefore, Table 3 decomposes the difference in the probability of dividend payments among the 'junk', 'moderate' and 'good' rated firms into the effect of firm characteristics and the effect of credit rating groups.

In panel $\mathrm{B}$, the same decomposition is carried out for the crisis and the non-crisis period separately, where the crisis period includes the years 2001-3, 2008-9, and 2012-13. The remaining years out of the entire sample period are defined as the non-crisis period. The actual probabilities on the diagonal line suggest that the junk group is most severely affected by the macroeconomic shocks as indicated in the probability decline from $15.8 \%$ to $11.2 \%$. In comparison, the proportion of dividend payers for the moderate group is reduced to some degree, but the good group is almost unaffected. One interesting pattern is that during the noncrisis period, the effect due to firm characteristics is greater than the effect of credit groups. For example, if we assume that the junk firms had the same firm characteristics as the moderate or the good group (vertical movement), then the junk firms' probability would increase from $15.8 \%$ to $34.2 \%$ and to $52.0 \%$, respectively. However, when we fix the level of firm characteristics and check the direct effect of the credit group (horizontal movement), then the hypothetical probability increases only to $33.8 \%$ and to $48.9 \%$. Similarly, moderate group's probability increases from $58.7 \%$ to $80.8 \%$ for the hypothetical change in firm characteristics, but it only increases to $71.8 \%$ for the hypothetical credit rating change to the good group.

The above pattern is completely reversed during the crisis period. Now, for the changes in the firm characteristics, the junk firms' hypothetical probability goes up only to $20.6 \%$ and to $31.0 \%$ (vertical movement), while the probability jumps to $35.5 \%$ and $55.5 \%$ for the changes in the credit group (horizontal movement). The same pattern is observed for the moderate group. The implication is that during the non-crisis period, firm characteristics of the traditional dividend forecast model play a major role in explaining dividends, but for the crisis period the explanatory power of firm characteristics drops and the effect of the credit groups becomes more important. Junk group firms under the stressful situation, such as a financial crisis, seem to take very conservative approach in dividend payments even if they possess the same level of firm characteristics as the firms of better rated groups.

Panel $\mathrm{C}$ reports the degree of information asymmetry for both crisis and non-crisis periods for each credit category of firms. Information asymmetry is measured by the relative rankings based on intangible assets, $R \& D$ expenses, firm size, number of shares, volatility of stock prices and market to book ratios, all of which are widely used as proxies for the degree of information asymmetry. For example, small size, intangible assets and high $\mathrm{R} \& \mathrm{D}$ expenses are positively related with the information asymmetry, while infrequently traded volatile stocks with high market to book ratios suffer more information failure. Every year, firms are classified into 100 portfolios based on each proxy and endowed with points from 1 to 100 , where 100 being the highest degree of information asymmetry. The weighted average of all points from all proxies are the final measure of information asymmetry.

As expected, Asymmetric Information index (AI index) increases monotonically as we move from the 'good' to the 'junk' group. In addition, during the crisis period, AI index increases from 64.84 to 68.03 for the 'junk' group of firms while the moderate and good groups show no deterioration in the information asymmetry. The conservative dividend policy of the junk group observed in panel B is believed to be linked with this elevated level of information asymmetry because the external financing for these firms are most difficult during the crisis period. As we reviewed in Table 2 logit regressions, the junk firms' intention of reserving cash turns out to be the greatest, which is also consistent with the conservative behavior of the junk group firms. On the contrary, firms of good rated group suffer no negative impact on the degree of information asymmetry and maintain high level of dividends for both crisis and noncrisis period.

\subsection{Decomposition Analysis}

\subsubsection{Theoretical Explanation of the Decomposition Method}


The odds of dividend payments for the junk group (group1, m=1) given the conditional distribution of firm characteristics for the junk group $(\mathrm{c} / \mathrm{m}=1)$ can be expressed as $\mathrm{O}_{\mathrm{m}=1, \mathrm{c} / \mathrm{m}=1}$. Similarly, the odds of dividend payments for the moderate group $(\mathrm{m}=2)$ given the conditional distribution of firm characteristics for the moderate group $(\mathrm{c} / \mathrm{m}=2)$ can

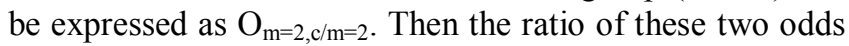
can be expressed as the product of the two terms:

$$
\frac{O_{m=2, c / m=2}}{O_{m=1, c / m=1}}=\frac{O_{m=1, c / m=2}}{O_{m=1, c / m=1}} \times \frac{O_{m=2, c / m=2}}{O_{m=1, c / m=2}}
$$

Here, $\mathrm{O}_{\mathrm{m}=1, \mathrm{c} / \mathrm{m}=2}$ is the hypothetical odds when the counter-factual conditional distribution of firm characteristics ' $\mathrm{c} / \mathrm{m}=2$ ' is used in place of ${ }^{\circ} \mathrm{c} / \mathrm{m}=1$ '. In other words, $\mathrm{O}_{\mathrm{m}=1, \mathrm{c} / \mathrm{m}=2}$ represents the counter-factual odds of group 1 when its firm characteristics are assumed to follow the conditional distribution of group 2. So, $\mathrm{O}_{\mathrm{m}=1, \mathrm{c} / \mathrm{m}=2}$ represents the counter-factual odds for junk firms $(\mathrm{m}=1)$, if they had the firm characteristics of moderate firms $(\mathrm{c} / \mathrm{m}=2)$. By taking the logs of both sides, we get the following:

$$
\begin{aligned}
\ln \left(O_{m=2, c / m=2}\right)- & \ln \left(O_{m=1, c / m=1}\right) \\
& =\left[\ln \left(O_{m=1, c / m=2}\right)-\ln \left(O_{m=1, c / m=1}\right)\right] \\
& +\left[\ln \left(O_{m=2, c / m=2}\right)\right. \\
& \left.-\ln \left(O_{m=1, c / m=2}\right)\right]
\end{aligned}
$$

The first term on the right-hand side of the equation captures the pure effect of firm characteristics $(\mathrm{m}=1, \mathrm{c} / \mathrm{m}=2$ vs $\mathrm{m}=1, \mathrm{c} / \mathrm{m}=1$ ) and the second term represents the group effect $(m=2, \mathrm{c} / \mathrm{m}=2$ vs $m=1, \mathrm{c} / \mathrm{m}=2)$. We define the group effect as 'direct' effect and the effect of firm characteristics as 'indirect effect'. The above equation, in this sense, decomposes the difference in the log odds into the effect due to firm characteristics and the effect due to credit rating groups. In equation (4), instead of $\mathrm{O}_{\mathrm{m}=1, \mathrm{c} / \mathrm{m}=2}$, if we use $\mathrm{O}_{\mathrm{m}=2, \mathrm{c} / \mathrm{m}=1}$, then the equation (5) can be expressed as follows:

$$
\begin{aligned}
\ln \left(O_{m=2, c / m=2}\right)- & \ln \left(O_{m=1, c / m=1}\right) \\
& =\left[\ln \left(O_{m=2, c / m=2}\right)-\ln \left(O_{m=2, c / m=1}\right)\right] \\
& +\left[\ln \left(O_{m=2, c / m=1}\right)\right. \\
& \left.-\ln \left(O_{m=1, c / m=1}\right)\right]
\end{aligned}
$$

Therefore, the difference in the log odds between group 1 and 2 can be decomposed based on either equation (5) or (6). We define the decomposition in equation (5) as method 1 and the decomposition in equation (6) as method 2. $<$ Table $4>$ reports both methods. In the comparison between the junk and the moderate group (marked $2 / 1$ in the table), the total effect of 2.346 consists of the indirect effect of 0.724 and the direct effect of 1.622 based on the method 1 .
In other words, the proportion of dividend difference between the group 1 and 2 that is attributable to the firm characteristics is roughly $30.9 \%(0.724 / 2.346)$. The remaining portion $(1.622 / 2.346$, or $69.1 \%)$ is the credit group effect. If we use the method 2 instead, then $62.9 \%$ $(1.476 / 2.346)$ is the credit group effect. The combined 'credit group effect' averages out two methods. For example, the credit group effect of 0.66 is the average of $69.1 \%$ and $62.9 \%$.

\subsubsection{Empirical Explanation of the Decomposition Results}

Table 4 reports all pair-wise comparisons between credit groups for both the crisis and the non-crisis periods. The credit group effect is most obviously observed during the crisis period. For example, the credit group effects of 0.496 , 0.483 , and 0.348 for the non-crisis period jump to 0.66 , 0.623 and 0.508 for the crisis period. In other words, for non-crisis periods, firm characteristics play a major role in explaining a firm's dividend policy, but once crisis periods begin, then the credit group effect dominates the effect of firm characteristics. This has an implication that the

\begin{tabular}{|c|c|c|c|c|c|c|}
\hline \multicolumn{7}{|c|}{ Panel A: Log odds ratios } \\
\hline & \multicolumn{3}{|c|}{ Crisis period } & \multicolumn{3}{|c|}{ Non-crisis period } \\
\hline & $2 / 1$ & $3 / 1$ & $3 / 2$ & $2 / 1$ & $3 / 1$ & $3 / 2$ \\
\hline Total & $\begin{array}{l}2.346^{*} \\
(0.097)\end{array}$ & $\begin{array}{l}4.132^{*} \\
(0.142)\end{array}$ & \begin{tabular}{|l|}
$1.786^{*}$ \\
$(0.092)$
\end{tabular} & $\begin{array}{l}2.025^{*} \\
(0.077)\end{array}$ & $\begin{array}{l}3.681^{*} \\
(0.114)\end{array}$ & $\begin{array}{l}1.655^{*} \\
(0.087)\end{array}$ \\
\hline Indirect1 & $\begin{array}{l}0.724 * \\
(0.088)\end{array}$ & $\begin{array}{l}1.275^{*} \\
(0.169)\end{array}$ & \begin{tabular}{|l|}
$0.815^{*}$ \\
$(0.047)$
\end{tabular} & $\begin{array}{l}1.019^{*} \\
(0.074)\end{array}$ & $\begin{array}{l}1.753^{*} \\
(0.138)\end{array}$ & $\begin{array}{l}1.088^{*} \\
(0.045)\end{array}$ \\
\hline Direct1 & $\begin{array}{l}1.622^{*} \\
(0.118)\end{array}$ & $\begin{array}{l}2.857^{*} \\
(0.210)\end{array}$ & $\begin{array}{l}0.971^{*} \\
(0.100)\end{array}$ & $\begin{array}{l}1.006^{*} \\
(0.095)\end{array}$ & $\begin{array}{l}1.927^{*} \\
(0.186)\end{array}$ & $\begin{array}{l}0.568^{*} \\
(0.088)\end{array}$ \\
\hline Indirect 2 & $\begin{array}{l}0.870^{*} \\
(0.045)\end{array}$ & $\begin{array}{l}1.839^{*} \\
(0.123)\end{array}$ & $\begin{array}{l}0.941^{*} \\
(0.079)\end{array}$ & $\begin{array}{l}1.022^{*} \\
(0.050)\end{array}$ & $\begin{array}{l}2.052^{*} \\
(0.129)\end{array}$ & $\begin{array}{l}1.071^{*} \\
(0.079)\end{array}$ \\
\hline Direct2 & $\begin{array}{l}1.476^{*} \\
(0.083)\end{array}$ & $\begin{array}{l}2.293^{*} \\
(0.157)\end{array}$ & $\begin{array}{l}0.845^{*} \\
(0.097)\end{array}$ & $\begin{array}{l}1.004 * \\
(0.076)\end{array}$ & $\begin{array}{l}1.629^{*} \\
(0.162)\end{array}$ & $\begin{array}{l}1.585^{*} \\
(0.108)\end{array}$ \\
\hline \multicolumn{7}{|c|}{ Panel B: Proportion of indirect effect } \\
\hline & \multicolumn{3}{|c|}{ Crisis period } & \multicolumn{3}{|c|}{ Non-crisis period } \\
\hline & $2 / 1$ & $3 / 1$ & $3 / 2$ & $2 / 1$ & $3 / 1$ & $3 / 2$ \\
\hline Method 1 & $\begin{array}{l}0.309^{*} \\
(0.038)\end{array}$ & $\begin{array}{l}0.309^{*} \\
(0.042)\end{array}$ & \begin{tabular}{|l|}
$0.456^{*}$ \\
$(0.033)$
\end{tabular} & $\begin{array}{l}0.503^{*} \\
(0.038)\end{array}$ & $\begin{array}{l}0.476^{*} \\
(0.042)\end{array}$ & $\begin{array}{l}0.657^{*} \\
(0.039)\end{array}$ \\
\hline Method 2 & $\begin{array}{l}0.371^{*} \\
(0.018)\end{array}$ & $\begin{array}{l}0.445^{*} \\
(0.029)\end{array}$ & $\begin{array}{l}0.527^{*} \\
(0.042)\end{array}$ & $\begin{array}{l}0.505^{*} \\
(0.026)\end{array}$ & $\begin{array}{l}0.557^{*} \\
(0.037)\end{array}$ & $\begin{array}{l}0.647^{*} \\
(0.053)\end{array}$ \\
\hline Aggregate & $\begin{array}{l}0.340^{*} \\
(0.023)\end{array}$ & $\begin{array}{l}0.377^{*} \\
(0.024) \\
\end{array}$ & \begin{tabular}{|l|}
$0.492 *$ \\
$(0.027)$
\end{tabular} & $\begin{array}{l}0.504^{*} \\
(0.028)\end{array}$ & $\begin{array}{l}0.517^{*} \\
(0.032) \\
\end{array}$ & $\begin{array}{l}0.652^{*} \\
(0.037) \\
\end{array}$ \\
\hline $\begin{array}{c}\text { Credit group } \\
\text { effect }\end{array}$ & 0.660 & 0.623 & 0.508 & 0.496 & 0.483 & 0.348 \\
\hline
\end{tabular}
traditional dividend forecast model may inaccurately reflect a firm's dividend behaviors during crisis periods. Based on the data, it seems reasonable to infer that at least for the crisis period, the corporate dividend policy may be influenced more by the credit ratings than by the endowed level of firm characteristics.

Table 4: Decomposition of firm characteristic effect and credit rating groups 
Another finding from Table 4 is that the gap between the group 1 and 2 and the gap between the group 1 and 3 are generally larger than the gap between the group 2 and 3 . For example, the credit group effect for the non-crisis period is 0.348 between the group 2 and 3, but this figure jumps to 0.496 and 0.483 for the group comparisons of 1 vs 2 and 1 vs 3 . Similar pattern is observed for the crisis period, where the group effect jumps from 0.508 to the whopping 0.66 and 0.623 . This implies that the distinction between the junk and the investment grade ratings is generally perceived as a greater building block that determines corporate dividend policies than the rating changes within the investment grade categories. Therefore, one who tries to predict a company's dividend policy should factor in the credit rating information, especially the investment vs non-investment grade rating records.

\subsection{Portfolio Approach}

Table 5 summarizes the probabilities of dividend payments for portfolios of junk rated firms sorted by risk and $\mathrm{M} / \mathrm{B}$, the two key variables that reduce dividends based on the regression results. 100 portfolios are constructed following DeAngelo et al. (2006) by varying risk and $\mathrm{M} / \mathrm{B}$ while fixing the other firm characteristics at their sample median levels.

Table 5: Contributions of individual predictors to the credit group effect

\begin{tabular}{|c|c|c|c|c|c|c|c|c|c|c|}
\hline & Low risk & 2 & 3 & 4 & 5 & 6 & 7 & 8 & 9 & High risk \\
\hline \multicolumn{11}{|c|}{ Panel A: Junk } \\
\hline Low M/B & .225 & .199 & .177 & .161 & .146 & .127 & .113 & .091 & .074 & .045 \\
\hline 2 & .220 & .187 & .168 & .153 & .133 & .120 & .105 & .085 & .067 & .040 \\
\hline 3 & .213 & .178 & .159 & .143 & .125 & .114 & .096 & .080 & .061 & .036 \\
\hline 4 & .205 & .174 & .149 & .132 & .121 & .107 & .091 & .074 & .057 & .033 \\
\hline 5 & .194 & .165 & .142 & .126 & .113 & .100 & .083 & .070 & .052 & .030 \\
\hline 6 & .188 & .156 & .131 & .120 & .106 & .096 & .076 & .066 & .047 & .029 \\
\hline 7 & .177 & .145 & .121 & .108 & .097 & .084 & .069 & .060 & .040 & .025 \\
\hline 8 & .161 & .124 & .108 & .096 & .082 & .072 & .058 & .052 & .034 & .021 \\
\hline 9 & .133 & .106 & .081 & .079 & .067 & .061 & .046 & .042 & .027 & .015 \\
\hline High M/B & .058 & .052 & .044 & .041 & .036 & .030 & .027 & .022 & .017 & .011 \\
\hline \multicolumn{11}{|c|}{ Panel B: Moderate } \\
\hline Low M/B & .432 & .408 & .387 & .369 & .353 & .329 & .312 & .281 & .252 & .196 \\
\hline 2 & .427 & .397 & .377 & .361 & .338 & .321 & .301 & .272 & .240 & .184 \\
\hline 3 & .421 & .388 & .368 & .350 & .328 & .314 & .289 & .264 & .230 & .174 \\
\hline 4 & .414 & .384 & .358 & .338 & .324 & .305 & .281 & .255 & .222 & .166 \\
\hline 5 & .404 & .376 & .350 & .331 & .314 & .296 & .270 & .248 & .212 & .160 \\
\hline 6 & .398 & .366 & .338 & .323 & .304 & .289 & .258 & .241 & .202 & .155 \\
\hline 7 & .389 & .354 & .326 & .307 & .292 & .272 & .247 & .229 & .187 & .145 \\
\hline 8 & .372 & .330 & .309 & .292 & .269 & .253 & .227 & .213 & .172 & .131 \\
\hline 9 & .342 & .307 & .270 & .265 & .245 & .233 & .202 & .193 & .153 & .112 \\
\hline High M/B & .231 & .219 & .200 & .192 & .179 & .164 & .153 & .138 & .119 & .093 \\
\hline \multicolumn{11}{|c|}{ Panel C: Good } \\
\hline Low M/B & .675 & .664 & .653 & .644 & .636 & .622 & .614 & .592 & .576 & .533 \\
\hline 2 & .671 & .655 & .644 & .636 & .622 & .614 & .602 & .582 & .561 & .515 \\
\hline 3 & .666 & .646 & .636 & .626 & .613 & .606 & .590 & .572 & .548 & .499 \\
\hline 4 & .660 & .643 & .626 & .615 & .608 & .597 & .581 & .562 & .538 & .486 \\
\hline 5 & .652 & .635 & .618 & .607 & .598 & .588 & .568 & .554 & .524 & .476 \\
\hline 6 & .646 & .627 & .607 & .600 & .588 & .581 & .554 & .545 & .509 & .467 \\
\hline 7 & .638 & .616 & .595 & .583 & .575 & .561 & .541 & .530 & .489 & .449 \\
\hline 8 & .623 & .592 & .577 & .567 & .549 & .539 & .515 & .509 & .465 & .423 \\
\hline 9 & .593 & .568 & .534 & .537 & .520 & .514 & .481 & .479 & .432 & .382 \\
\hline High M/B & .467 & .463 & .444 &. .441 & .429 & .414 & .404 & .390 & .369 & .339 \\
\hline
\end{tabular}

This method is beneficial in assessing the marginal contribution of individual predictors. Panel A reports the actual probabilities for junk firms, while Panel B (C) reports the counter-factual probabilities if the same junk firms with the same firm characteristics were classified as the moderate (good) group. Therefore, the difference between panel A and panel B (or C) can be interpreted as the pure effect of different credit groups after controlling for the difference in firm characteristics.

If you look at the numbers in panel $A$, both risk and $\mathrm{M} / \mathrm{B}$ reduce the probability of dividends. The marginal impact, though, is slightly bigger for the risk as it causes on average $14.9 \%$ decrease in dividends, while $\mathrm{M} / \mathrm{B}$ causes $10.2 \%$ decrease. Rating upgrade from the junk to the moderate group (from panel A to B) increases the probability of dividends for all 100 portfolios. Particularly, the increase in 
probabilities is most noticeable for the low risk and low $\mathrm{M} / \mathrm{B}$ groups. In other words, the potential payer groups seem to be more affected by the credit ratings. High risk and high $\mathrm{M} / \mathrm{B}$ groups are non-payer groups anyway and are not so much affected by the credit ratings as the potential payer groups. For example, firms that belong to the upper left hand side triangle (low risk and low $\mathrm{M} / \mathrm{B}$ ), on average, show $20.5 \%$ increase in the probability when they were classified as the moderate group, while the firms that belong to the lower right hand side of the table (high risk and high M/B) manifest only $15.5 \%$ increase. Similar pattern is observed for panel $\mathrm{C}$ and there exists an obvious credit group effect because all 100 portfolios show a clear jump in the estimated probabilities when assumed to be upgraded in their credit ratings. Better rated firms seem to be exposed to a more favorable environment in the area of dividend payments. Even if the endowed level of firm characteristics are the same, firms with higher credit ratings turn out to be more generous in paying dividends. Therefore, firms of different credit groups have different sensitivity with respect to each firm characteristic, and we cannot say that firms react to common dividend predictors exactly the same way as the traditional dividend forecast model implicitly assumes.

\subsection{Robustness Check}

Table 6 reports the robustness results of the credit group effect by dichotomizing the total sample as the investment and the non-investment grade. The investment grade group now includes both moderate and good rated firms.

Table 6: Robustness check of two group classification

\begin{tabular}{|c|c|c|c|c|c|c|}
\hline \multicolumn{8}{|c|}{ Panel A: Log odds ratios } \\
\hline & \multicolumn{2}{|c|}{ Crisis period } & \multicolumn{2}{c|}{ Non-crisis period } & \multicolumn{2}{c|}{ Entire sample } \\
\cline { 2 - 7 } & $\begin{array}{c}\text { Estimated } \\
\text { coefficient }\end{array}$ & $\begin{array}{c}\text { Bootstrap } \\
\text { Std. error }\end{array}$ & $\begin{array}{c}\text { Estimated } \\
\text { coefficient }\end{array}$ & $\begin{array}{c}\text { Bootstrap } \\
\text { Std. error }\end{array}$ & $\begin{array}{c}\text { Estimated } \\
\text { coefficient }\end{array}$ & $\begin{array}{c}\text { Bootstrap } \\
\text { Std. error }\end{array}$ \\
\hline Total & $2.668^{*}$ & 0.075 & $2.363^{*}$ & 0.093 & $2.503^{*}$ & 0.070 \\
\hline Indirect1 & $0.871^{*}$ & 0.112 & $1.225^{*}$ & 0.107 & $1.071^{*}$ & 0.075 \\
\hline Direct1 & $1.797^{*}$ & 0.126 & $1.138^{*}$ & 0.111 & $1.433^{*}$ & 0.098 \\
\hline Indirect2 & $1.149^{*}$ & 0.043 & $1.328^{*}$ & 0.055 & $1.246^{*}$ & 0.034 \\
\hline Direct2 & $1.519^{*}$ & 0.073 & $1.036^{*}$ & 0.089 & $1.257^{*}$ & 0.064 \\
\hline \multicolumn{8}{|c|}{ Panel B: Proportion of indirect effect } \\
\hline Method1 & $0.327^{*}$ & 0.041 & $0.518^{*}$ & 0.042 & $0.428^{*}$ & 0.031 \\
\hline Method2 & $0.431^{*}$ & 0.016 & $0.562^{*}$ & 0.025 & $0.498^{*}$ & 0.015 \\
\hline Aggregate & $0.379^{*}$ & 0.025 & $0.540^{*}$ & 0.029 & $0.463^{*}$ & 0.020 \\
\hline $\begin{array}{c}\text { Credit group } \\
\text { effect }\end{array}$ & 0.621 & 0.460 & 0.537 \\
\hline
\end{tabular}

*Significant at $1 \%$.

For the non-crisis period, the indirect effect, or the effect due to firm characteristics, explains $54 \%$ of the dividend difference and the remaining $46 \%$ is the credit group effect. On the contrary, for the crisis period, the effect of firm characteristics drops to $37.9 \%$ and the remaining $62.1 \%$ is the credit group effect. Consistence with the main results from the three group classification, firm characteristics explain dividend behaviors relatively well during the noncrisis period, but for the crisis period, the explanatory power of firm characteristics drops and the credit group effect plays a dominant role in explaining dividends.

\section{Conclusions}

Historically, better credit rated firms have shown consistently higher propensity to pay dividends and they have been less susceptible to the outside macroeconomic shocks than the lower rated counterparts. Based on the traditional dividend forecast model, we decompose the dividend difference between credit groups into a part that can be explained by the firm characteristics and a residual part that is attributable to the group specific effect. A significant portion of dividend difference comes from the sensitivity difference. For example, firms that belong to the higher rated credit group respond more favorably to the positive dividend determinants, such as size and profitability, while the firms that belong to the lower credit rated group respond more negatively to the negative firm characteristics such as risk and $\mathrm{M} / \mathrm{B}$. As a result, better (poor) rated firms have a higher (lower) chance of dividend payments than what the traditional dividend forecast model would predict. In our portfolio analysis, if junk firms with the same level of firm characteristics, were classified as higher credit groups, they all show the elevated hypothetical probabilities of dividend payments.

It turns out that the credit ratings affect the way a firm respond to the firm characteristics, and the traditional dividend forecast model that lumps all the firms and derives a common dividend forecast model may fail to capture this systematic difference between different credit groups. The credit group effect is most noticeable between the junk grade and the investment grade firms. Junk rated firms are weaker in dealing with risks and they show the elevated level of information asymmetry during the crisis period. Therefore, they seem to take a more conservative approach in the dividend policy by reserving more internal cash in preparation for future investments. Starting from the traditional dividend forecast model that assumes the homogeneous response of firms, we move one step further by proposing the possibility that firms may react differently to the same firm characteristics depending on which credit group they belong to. Based on the decomposition results, the unexplained part increases significantly during the crisis period and the knowledge of credit ratings becomes crucial 
in understanding dividend behaviors.

\section{References}

Baker, M., \& Wurgler, J. (2004). Appearing and disappearing dividends: The link to catering incentives. Journal of Financial Economics, 73(2), 271-288.

Blinder, A. S. (1973). Wage discrimination: Reduced form and structural estimates. The Journal of Human Resources, 8(4), 436-455.

DeAngelo, H., DeAngelo, L., \& Stulz, R. M. (2006). Dividend policy and the earned/contributed capital mix: A test of the lifecycle theory. Journal of Financial Economics, 81(2), 227-254.

Erikson, R., Goldthorpe, J. H., Jackson, M., Yaish, M., \& Cox, D. R. (2005). On class differentials in educational attainment. Proceedings of the National Academy of Science, 102(27), 9730-9733.

Fama, E. F., \& French, K. R. (2001). Disappearing dividends: Changing firm characteristics or lower propensity to pay? Journal of Financial Economics, 60(1), 3-43.

Grullon, G., Michaely, R., \& Swaminathan, B. (2002). Are dividend changes a sign of firm maturity? Journal of Business, 75(3), 387-424.

Hoberg, G., \& Prabhala, N. R. (2009). Disappearing dividends, catering, and risk. Review of Financial Studies, 22(1). 79-116.
Jann, B. (2008). The Blinder-Oaxaca decomposition for linear regression models. The Stata Journal, 8(4), 453479.

Khieu, H. D., \& Pyles, M. K. (2016). The influence of a credit rating change on dividend and investment policy interactions. Financial Review, 51(4), 579-611.

Kim, T. K., \& Kim, I. J. (2019). Credit ratings and dividend policy. The Korean Journal of Financial Engineering, 18(2), 27-49.

Oaxaca, R. (1973). Male-female wage differentials in urban labor markets. International Economic Review, 14(3), 693-709.

Park, H. J., \& Yoo, Y. T. (2019). Differences among credit rating agencies and the information environment. Journal of Asian Finance, Economics and Business, 6(2), 25-32.

Shin, M. S., Lee, J. I., \& Jung, H. Y. (2017). The effects of credit rating change on corporate dividend policy. Journal of International Trade and Commerce, 13(3), 563-585.

Sufi, A. (2009). The real effects of debt certification: Evidence from the introduction of bank loan ratings. Review of Financial Studies, 22(4), 1659-1691.

Tahir, M., \& Mushtaq, M. (2016). Determinants of dividend payout: Evidence from listed oil and gas companies of Pakistan. Journal of Asian Finance, Economics and Business, 3(4), 25-37. 